\title{
Composição florística e fitossociológica em manancial de Brejo de Altitude
}

\author{
Floristic and phytosociological composition in a High Altitude Wetland Spring \\ Composición florística y fitosociológica en un Manantial Húmedo de Altitud
}

Recebido: 14/03/2021 | Revisado: 21/03/2021 | Aceito: 24/03/2021 | Publicado: 01/04/2021

\author{
Danielle de Siqueira Jansen \\ ORCID: https://orcid.org/0000-0003-4543-3777 \\ Secretaria de Desenvolvimento Rural e Meio Ambiente, Brasil \\ E-mail: daniellejansen1@ hotmail.com \\ Edilma Pereira Gonçalves \\ ORCID: https://orcid.org/0000-0001-5150-7088 \\ Universidade Federal do Agreste de Pernambuco, Brasil \\ E-mail: edilmapg@hotmail.com \\ Jeandson Silva Viana \\ ORCID: https://orcid.org/0000-0002-8958-2873 \\ Universidade Federal do Agreste de Pernambuco, Brasil \\ E-mail: jeandsonsv@yahoo.com.br \\ João Paulo Goes da Silva Borges \\ ORCID: https://orcid.org/0000-0003-2707-6489 \\ Universidade Federal do Agreste de Pernambuco, Brasil \\ E-mail: joaopaulobiologia4@gmail.com \\ Débora Teresa da Rocha Gomes Ferreira de Almeida \\ ORCID: https://orcid.org/0000-0001-8644-0274 \\ Faculdades Nova Esperança, Brasil \\ E-mail: debora_teresa@hotmail.com \\ Horasa Maria Lima da Silva Andrade \\ ORCID: https://orcid.org/0000-0002-5366-6610 \\ Universidade Federal do Agreste de Pernambuco, Brasil \\ E-mail: horasaa@gmail.com \\ Monalisa Alves Diniz da Silva \\ ORCID: https://orcid.org/0000-0001-9052-7380 \\ Universidade federal Rural de Pernambuco, Brasil \\ E-mail: monallyysa@yahoo.com.br
}

\begin{abstract}
Resumo
A Mata Attântica é um dos principais biomas Brasileiros que se estende desde o Rio Grande do Norte ao Rio Grande do Sul. Dentro desse ecossistema, destaca-se as formações de floresta estacional semidecidual montana (brejos de altitudes). Diante disso, o objetivo do trabalho foi investigar a composição florística e fitossociológico num trecho de mata ciliar de um fragmento de Mata Attântica em Ihumas, localizada no município de Garanhuns - PE. O estudo foi desenvolvido em um trecho de Mata Ciliar na comunidade rural de Inhumas, município de Garanhuns-PE. A área foi delimitada em 07 parcelas de $10 \times 10 \mathrm{~m}$, contendo 0,07 ha da área total amostrada. Em cada parcela foram amostrados todos os indivíduos arbóreos vivos, com DAP $\geq 5 \mathrm{~cm}$. No fragmento de Mata Ciliar na Comunidade de Inhumas apontou a ocorrência de 257 indivíduos arbóreos distribuídos em 14 famílias, 18 gêneros e 23 espécies. As Famílias com maior número de riqueza de espécies foram: Fabaceae (cinco ssp.), Sapindaceae (três ssp.) Myrtaceae e Melastomataceae (duas ssp). As espécies Byrsonima sericea DC., Myrcia bela Cambess., Cupania impressinervia e Casearia sylvestris $\mathrm{Sw}$. com frequência absoluta de $100 \%$, sendo $44 \%$ das espécies classificadas como secundária inicial e $73 \%$ possuem dispersão zoocórica. A área possui alta riqueza florística estando em fase inicial do desenvolvimento sucessional, sendo a espécie Cupania impressinervia Acev.-Rodr. a mais representada na posição sociológica do extrato vertical arbóreo, ocupando os três extratos.
\end{abstract}

Palavras-chave: Diversidade de espécie; Vegetação da mata atlântica; Floresta montana.

\begin{abstract}
The Atlantic Forest is one of the main Brazilian biomes that extends from Rio Grande do Norte to Rio Grande do Sul. Within this ecosystem, stands out the formations of semi-deciduous seasonal forest Montana (marshes of altitudes). Therefore, the objective of the study was to investigate the floristic and phytosociological composition in a section of riparian forest of a fragment of Atlantic Forest in Ihumas, located in the municipality of Garanhuns - PE. The study was developed in a section of Mata Ciliar in the rural community of Inhumas, municipality of GaranhunsPE. The area was delimited in 07 plots of $10 \times 10 \mathrm{~m}$, containing 0.07 ha of the total sampled area. In each plot were sampled all live arboreal individuals, with DAP $5 \mathrm{~cm}$. In the fragment of Mata Ciliar in the Community of Inhumas, 257 tree individuals were found distributed in 14 families, 18 genera and 23 species. The families with the highest number of species richness were: Fabaceae (five ssp.), Sapindaceae (three ssp.) Myrtaceae and Melastomataceae (two
\end{abstract}


ssp). The species Byrsonima sericea DC., Myrcia bela Cambess., Cupania impressinervia and Casearia sylvestris Sw. with an absolute frequency of $100 \%, 44 \%$ of the species classified as initial secondary and $73 \%$ have zoochoric dispersion. The area has high floristic richness being in the early phase of the successive development, being the species Cupania impressinervia Acev.-Rodr. the most represented in the sociological position of the arboreal vertical extract, occupying the three extracts.

Keywords: Species diversity; Vegetation of the atlantic forest; Montane rainforest.

\section{Resumen}

El Bosque Atlántico es uno de los principales biomas brasileños que se extiende desde Rio Grande do Norte hasta Rio Grande do Sul. Dentro de ese ecosistema, se destacan las formaciones de bosque estacional semidecidual Montana (matorrales de altitudes). Delante de eso, el objetivo del trabajo fue investigar la composición florística y fitosociológica en un trecho de mata ciliar de un fragmento de Mata Atlántica en Ihumas, localizada en el municipio de Garanhuns - PE. El estudio se desarrolló en un tramo de Mata Ciliar en la comunidad rural de Inhumas, municipio de Garanhuns-PE. La zona fue delimitada en 07 parcelas de 10 × $10 \mathrm{~m}$, conteniendo 0,07 ha de la área total muestreada. En cada parcela fueron muestreados todos los individuos arbóreos vivos, con DAP $5 \mathrm{~cm}$. En el fragmento de Mata Ciliar en la Comunidad de Inhumas apuntó la presencia de 257 individuos arbóreos distribuidos en 14 familias, 18 géneros y 23 especies. Las familias con mayor número de riqueza de especies fueron: Fabaceae (cinco ssp.), Sapindaceae (tres ssp.) Myrtaceae y Melastomataceae (dos ssp). Las especies Byrsonima sericea DC., Myrcia bella Cambess., Cupania impressinervia y Casearia sylvestris Sw. con una frecuencia absoluta del $100 \%$, siendo el $44 \%$ de las especies clasificadas como secundaria inicial y el $73 \%$ poseen dispersión zoocórica. El área posee alta riqueza florística estando en fase inicial del desarrollo sucesorio, siendo la especie Cupania impressinervia Acev.Rodr. la más representada en la posición sociológica del extracto vertical arbóreo, ocupando los tres extractos.

Palabras clave: Diversidad de espécies; Vegetación del bosque atlântico; Bosque húmedo de montaña.

\section{Introdução}

A Mata Atlântica é um dos principais biomas brasileiros que se estende por toda porção leste do país e originalmente ocupava 1.300.000 km² da costa brasileira, desde o Rio Grande do Norte ao Rio Grande do Sul (Mma, 2002; Galindo Leal \& Câmara, 2005). Sendo Composta por formações Floresta Ombrófila Densa; Floresta Ombrófila Mista ou Mata de Araucárias, Floresta Ombrófila Aberta, Floresta Estacional Semidecidual e Floresta Estacional Decidual, podendo ocorrer a inserção de ecossistemas como: Manguezais, Vegetações de Restingas, Campos de Altitude, Brejos Interioranos e Encraves Florestais do Nordeste (Mma, 2012).

Estudos florísticos e taxionômico realizados nas últimas décadas revelaram a ocorrência de 16.451 espécies plantas vasculares, das quais 20,4\% estão presenta nas formações de floresta estacional semidecidual montana (brejos de altitudes) (Flora do Brasil, 2020) Essa formação vegetal se caracteriza por apresenta precipitações média de 240 a 900 mm, chuvas orográfica e fragmentações florestal isoladas (ilhas) de florestas úmidas nas regiões do semi-árido, com vegetação caatinga distribuída no seu entorno (Araújo et al., 2019). A presenta dessa biodiversidade florestal inserida no domínio do semi-árido ocorre devido a fatores topográficos formado por planaltos e chapadas (altitude de 600 a 1.100 m.a.n.m) em que permite um incremento na média da pluviosidade nos diversos extratos (Tabarelli \& Santos, 2004). Segundo Porto et al. (2004) os brejos são refúgios isolados das florestas atlânticas nordestinas no meio da caatinga, abrigando plantas da floresta amazônica e vegetação serrana do sul e sudeste de brasil.

Estudos sobre a composição e estrutura da Mata Atlântica, bem como, Suas Formações vegetativas são importantes para a caracterização dos aspectos da ecologia regional, registro de espécies, densidade e dominância de indivíduos proporcionando a identificação de espécies ameaçadas, recuperação de áreas degradadas, estratégias de uso racional das espécies, além de oferecer subsídios para criação de políticas de conservação (Brito et al., 2007). Torres et al. (2017) ressaltam a importância desses estudos para maior conhecimento sobre a diversidade local, entendimento do estágio de regeneração de floresta, estoque da biomassa e carbono em florestas tropicais.

Diversos levantamento fitossociológico e florísticos em floresta estacional semidecidual montana (brejos de altitudes) tem sido ampliado nos últimos anos, destacando os trabalhos de: Meira-Neto \& Martins (2002); Marangon et al. 
(2003); Silva et al. (2004); Rodal et al. (2005); Cunha et al. (2013); Cunha \& Silva Júnior (2014); Lorenzoni-Paschoa (2019).

Apesar de existir alguns estudos com a temática, ainda há lacunas de informações básicas sobre a ecologia em brejos de altitudes e nesse contexto o objetivo do trabalho foi investigar a composição florística e fitossociológica em um trecho de vegetação no entorno do manancial de Inhumas no município de Garanhuns - PE.

\section{Metodologia}

\subsection{Descrição da área de estudo}

O estudo foi desenvolvido em um trecho de Mata Ciliar localizada na comunidade rural de Inhumas, município de Garanhuns, Agreste Meridional de Pernambuco. A comunidade conta com um importante manancial (Barragem de Inhumas) e área de estudo abrange 0,13ha, situado numa encosta com 7,8\% de declividade. A temperatura média vária de 15 a 21 (Apac, 2018) localizada na coordenada $8^{\circ} 59^{\prime}$ '21' S e 36²3'09” W, a 37 km de distância da zona urbana de Garanhuns, via BR 424 (Google, 2018) (Figura 1).

Figura 1. Área de estudo de um trecho de Mata Ciliar na Comunidade Rural de Inhumas, Garanhuns - PE. (A) Pernambuco e suas respectivas mesorregiões; (B) Mesorregião do Agreste de Pernambuco, com destaque para o município de Garanhuns; (C) Vista global do Manancial de Inhumas; (D) Área de estudo, trecho de Mata Ciliar.

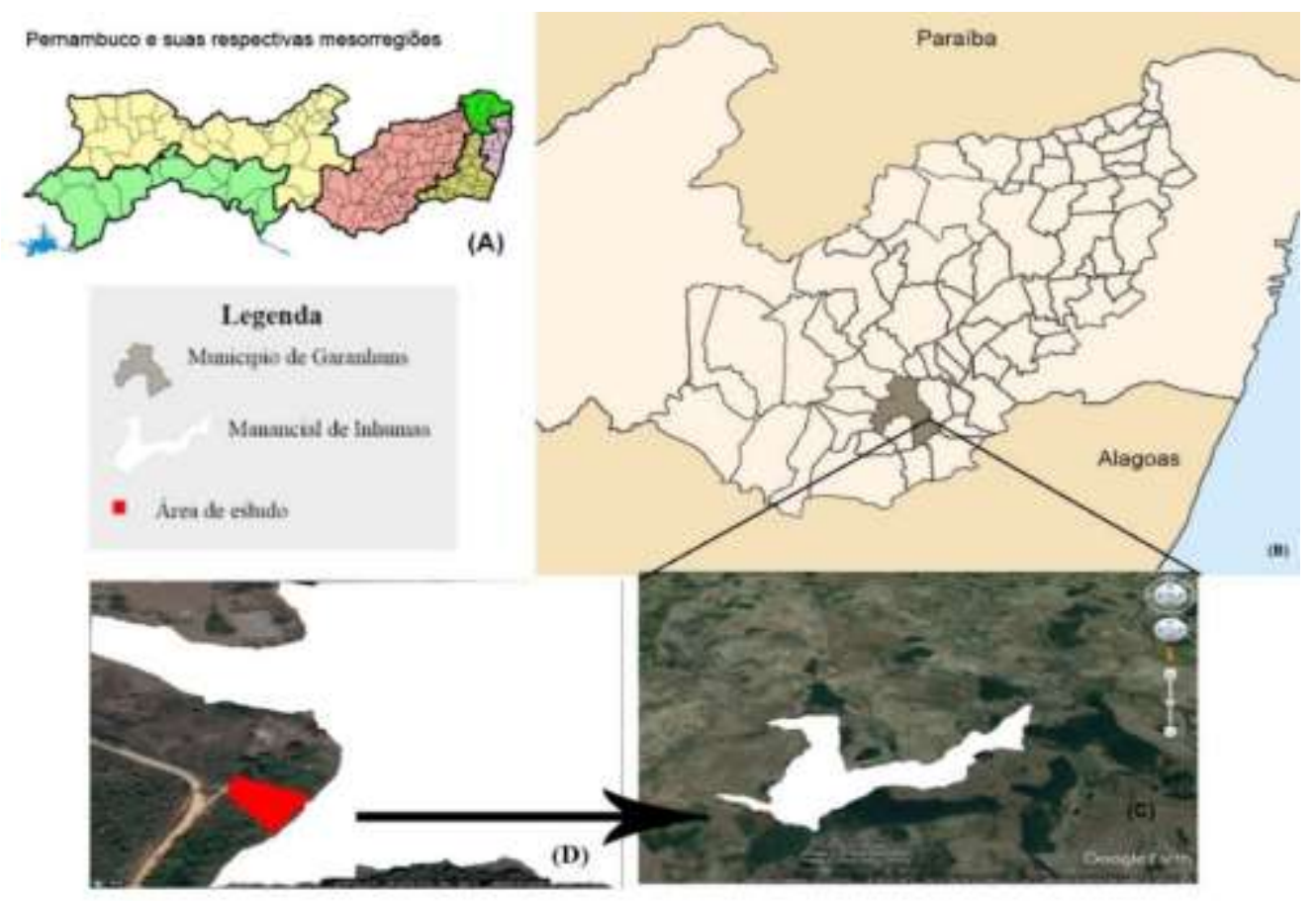

Fonte: Google (2018); APAC (2018).

De acordo com a Gomes (2018) a barragem contém cerca de sete milhões de $\mathrm{m}^{3}$ sendo responsável por abastecer uma parte da população de Garanhuns, o município de Palmerina, povoados de Olho d'água e Poço Comprido do município de Correntes - PE. Além de fazer divisa com os municípios de São João, Palmerina e Correntes.

A fitofisionomia se encontra bastante alterada devido as práticas de bovinocultura extensiva, em que a vegetação nativa é substituída por pastagens, que estão degradadas, devido ao manejo de plantio morro abaixo. A vegetação ciliar no 
entorno do manancial de Inhumas apresenta-se fragmentada, onde na porção leste/sul contém uma boa reserva de mata ciliar, com a parte da posição norte/oeste ausente, com severas ocorrências de erosão laminar.

\subsection{Levantamento Florístico e Fitossociológico}

Para coleta e caracterização da vegetação foi realizado o estudo florístico e fitossociológico no entorno do manancial de Inhumas, na qual foi empregado o Método de Parcelas proposta por Müller Dombois e Ellenberg (1974).

A área foi delimitada em 07 parcelas de $10 \times 10 \mathrm{~m}$, contendo 0,07 ha da área total amostrada, dispostas sistematicamente, ou seja, alocadas em um padrão regular na área de estudo, dentro da unidade amostral de 0,13 ha.

Em cada parcela foram amostrados todos os indivíduos arbóreos vivos, com DAP $\geq 5 \mathrm{~cm}$, numerados em ordem crescente utilizando fita crepe. Para cada indivíduo foi anotado o diâmetro a 1,30 m do nível do solo com o auxílio de uma fita métrica e a altura estimada com auxílio de uma vara graduada.

\subsection{Análise Florística}

Em campo, foram coletados ramos férteis de cada individuou para confecção de exsicatas de acordo com a metodologia proposta por Peixoto \& Maia (2013). A classificação das espécies foi adotada com base no sistema Angiosperm Phylogeny Group (APG) III. Os níveis taxonômicos de família, gênero e espécie foram estabelecidos com base nos trabalhos de Lorenzi (2008), Souza e Lorenzi (2012); e chave dicotômica virtual para nível de espécies (Flora do Brasil, 2020). Após a identificação foi determinado os Grupo Ecológico (GE) subdividido em Pioneira (P); Secundária inicial (SI); Secundária tardia (ST); Sem classificação (SC) e os Mecanismo de Dispersão (MD) subdividido em Zoocoria (ZOO); Anemocoria (ANE); Autocoria (AUT); Barocoria (BAR).

\subsection{Análise fitossociologia}

\subsubsection{Parâmetros Fitossociológicos Horinzontais:}

Número de indivíduo (NI): representado pela quantificação de indivíduo total encontrado na área de estudo

Número da parcela em que a espécie foi amostrada (NA): representa quantas parcelas tem ocorrência de cada espécie coletada.

Somatório da área Basal (SAB): representa a ocupação total que cada indivíduo (área por madeira) em um hectare. O resultado é expresso em m²/há (Carvalho, 2019)

Densidade Absoluta (DAi): corresponde ao número de indevidos de cada espécies por unidade de área (Carvalho, 2019), calculada com base na equação:

$$
D A i=\frac{\text { Número total de Individuos amostrados }}{\text { Ârea total amostrada, em hectare }}
$$

Densidade Relativa (DRi): corresponde ao número total de indevidos de cada espécies por unidade de área (Carvalho, 2019), empresa em porcentagem com base na equação:

$$
D R i=\left(\frac{\text { Número total de Indivíduos amostrados }}{\text { Área total amostrada, em hectare }}\right) \times 100
$$

Frequência Absoluta (FAi): Corresponde ao número de ocorrência das especiais nas diferentes parcelas amostradas no levantamento (Carvalho, 2019), calculada com base na equação. 


$$
F A i=\left(\frac{\text { Número de Parcelas que ocorre uma dada espécie }}{\text { Número Total de parcelas }}\right) \times 100
$$

Frequência Relativa (FRi): Corresponde a porcentagem da frequência absoluta em relação ao somatório de todas as frequências absolutas pré-estabelecidas (Carvalho, 2019).

$$
F R i=\left(\frac{\text { Frequência Absoluta de determinada Espécie }}{\text { Somatório das Frequências Absolutas de todas as Espécies }}\right) \times 100
$$

Dominância Absoluta (DoAi): Representa a influência de cada espécie na comunidade (Araújo et al., 2020), calculada com base na equação.

$$
\text { DoAi }=\left(\frac{\text { Somátorio da årea basal dos indivíduos de cada espécie, em m }}{\text { Ârea Amostrada, em hectare }}\right)
$$

Dominância Relativa (DoR): Corresponde a participação em porcentagem de cada indivíduo em relação a área basal (Araújo et al., 2020).

$$
\mathrm{DoR}=\left(\frac{\text { Dominância Absoluta de determinada Espécie, } \mathrm{em} \mathrm{m}^{2} / \mathrm{ha}}{\text { Somatorio total das dominnâncias de todas as espécies, } \mathrm{em} \mathrm{m}^{2} / \mathrm{ha}}\right) \times 100
$$

Valor de importância (VI): Representa a importância ecológica de cada espécie em termos de distribuição horizontal (Carvalho, 2019).

$$
\text { VI = Densidade relativa }(\%) \text { + Frequência relativa }(\%) \text { + Dominância relativa (\%) }
$$

Valor de Importância em porcentagem (VI \%): corresponde ao valor médio a de importância ecológica de cada espécie em termos de distribuição horizontal (Carvalho, 2019).

$$
\text { VI } \%=\frac{\text { Valor de Importância }}{3}
$$

Valor de cobertura (VC): Representa a importância ecológica de cada espécie em termos de distribuição horizontal com base na densidade relativa de cada espécies e sua dominância (Carvalho, 2019).

$$
\text { VC }=\text { Densidade relativa }(\%)+\text { Dominância relativa (\%) }
$$

VC \%: Valor de Cobertura em porcentagem. Corresponde ao valor médio a de importância ecológica de cada espécie em termos de distribuição horizontal com base na densidade relativa de cada espécies e sua dominância (Carvalho, 2019). 


\section{VC $\%=\frac{\text { valor de cobertura }}{2}$}

\subsubsection{Parâmetro Fitossociológico Vertical}

Os extratos verticais foram determinados da seguinte forma:

Estrato 1: até 1/3 da ht (m)

Estrato 2: ht $>1 / 3$ e ht $\leq 1 / 6(\mathrm{~m})$

Estrato 3: ht acima de 1/6 (m)

ht $=$ altura total da j-ésima árvore individual.

Valor Fitossociológico: corresponde ao número total de cada espécies coletado na amostra em relação a quantidade total dos indivíduo da amostra (Carvalho, 2019).

$$
\begin{aligned}
& \text { VF1 } \%=\frac{\text { Número total de Individuos no Extrato Amostrado }}{2 \text { Número Total de indivíduos amostrados }} \\
& \text { VF2 } \%=\frac{\text { Número total de Individuos no Extrato Amostrado }}{\text { Número Total de indivíduos amostrados }} \\
& \text { VF3 } \%=\frac{\text { Número total de Indivíduos no Extrato Amostrado }}{\text { Número Total de indivíduos amostrados }}
\end{aligned}
$$

OS parâmetros de Posição Sociológica Absoluta (PSAi) e Posição Sociológica Relativa (PSRi) que refere-se a importância de cada espécies, tendo como base sua participação nos estratos foram determinados com base na metodologia proposta por Mueller-Dombois \& Ellenberg (1974).

\section{Resultados e Discussão}

\subsection{Composição Florística}

No fragmento de Mata Ciliar na Comunidade de Inhumas foram encontrados 257 indivíduos arbóreos distribuídos em 14 famílias, 18 gêneros e 23 espécies, em indivíduos com DAP $\geq 5 \mathrm{~cm}$, sendo 3 espécies identificadas somente a nível de gênero e 1 sem classificação (Tabela 1). As Famílias com maior número de riqueza de espécies foram a Fabaceae (cinco ssp.), Sapindaceae (três ssp.) Myrtaceae e Melastomataceae (duas ssp) e as demais famílias apresentando 1 espécie (Tabela 1). Desse conjunto de famílias com uma espécie, a maior raridade foi apresentada pelas famílias Annonaceae, Myrsinaceae e Urticaceae, as quais foram representadas por apenas um indivíduo independente do seu DAP, ao contrário da família Anacardiaceae que também foi encontrado um indivíduo com $\mathrm{DAP} \geq 5 \mathrm{~cm}$. 
Tabela 1. Famílias com suas espécies (nome científico e nome popular) da área amostrada no trecho de mata ciliar fragmentada no entorno do manancial de Inhumas, Garanhuns - PE. Número de Indivíduo (NI); Grupo Ecológico (GE): Pioneira (P); Secundária inicial (SI); Secundária tardia (ST); Sem classificação (SC). Mecanismo de Dispersão (MD): Zoocoria (ZOO); Anemocoria (ANE); Autocoria (AUT); Barocoria (BAR). *Família e espécies Não Identificadas (NI).

\begin{tabular}{|c|c|c|c|c|c|}
\hline FAMÍLIAS & ESPÉCIES & $\begin{array}{c}\text { NOME } \\
\text { POPULAR }\end{array}$ & NI & GE & MD \\
\hline ANACARDIACEAE & Tapirira guianensis Aubl. & Pau pombo & 1 & SI & $\mathrm{ZOO}$ \\
\hline ANNONACEAE & Guatteria australis A.St.-Hil. & Pindaúva preta & 1 & SI & $\mathrm{ZOO}$ \\
\hline \multirow{2}{*}{ CLUSIACEAE } & Vismia brasiliensis Pers. & Lacre & 8 & $\mathrm{P}$ & $\mathrm{ZOO}$ \\
\hline & & & & & AUT, BAR, ZOO \\
\hline \multirow{6}{*}{ FABACEAE } & Hymenaea courbaril $\mathrm{L}$. & Jatobá & 21 & ST & ANE \\
\hline & Machaerium hirtum (Vell) & Chifre de bode & 9 & $\mathrm{P}$ & ANE \\
\hline & Stellfeld & & & & \\
\hline & Bowdichia virgilioides Kunth & Sucupira preto & 2 & $\mathrm{ST}$ & ANE E ZOO \\
\hline & Erythrina velutina Willd & Mulungu & 1 & $\mathrm{P}$ & ANE \\
\hline & ENI $1 *$ & NI 1 & 5 & $\mathrm{SC}$ & $\mathrm{ZOO}$ \\
\hline FLACOURTIACEAE & Casearia sylvestris $\mathrm{Sw}$. & Caimbim & 22 & SI & $\mathrm{ZOO}$ \\
\hline \multirow[t]{2}{*}{ MALPIGHIACEAE } & Byrsonima sericea DC. & Murici & 33 & SI & $\mathrm{ZOO}$ \\
\hline & Miconia sp. & Cinzeiro & 17 & $\mathrm{SC}$ & $\mathrm{ZOO}$ \\
\hline MELASTOMATACEAE & Miconia minutiflora Triana & $\begin{array}{l}\text { Cinzeiro da } \\
\text { folha grande }\end{array}$ & 6 & $\mathrm{P}$ & $\mathrm{ZOO}$ \\
\hline \multirow[t]{2}{*}{ MYRSINACEAE } & Myrsine umbellata Mart. & Pororocão & 1 & SI & $\mathrm{ZOO}$ \\
\hline & Myrcia selloi (Spreng.) N. & Cambui & 8 & $\mathrm{ST}$ & $\mathrm{ZOO}$ \\
\hline \multirow[t]{2}{*}{ MYRTACEAE } & Silveria & & & & \\
\hline & Myrcia bela Cambess. & Murta & 29 & SI & $\mathrm{ZOO}$ \\
\hline RUTACEAE & Zanthoxylum rhoifolium Lam. & Laranjinha & 4 & $\mathrm{P}$ & $\mathrm{ZOO}$ \\
\hline \multirow{4}{*}{ SAPINDACEAE } & Talisia esculenta (A.St.-Hil.) & Pitomba & 24 & SI & $\mathrm{ZOO}$ \\
\hline & Radlk. & & & & \\
\hline & $\begin{array}{l}\text { Cupania impressinervia Acev.- } \\
\text { Rodr. }\end{array}$ & Caboatã do rêgo & 34 & SI & $\mathrm{ZOO}$ \\
\hline & Cupania oblongifolia Mart. & $\begin{array}{l}\text { Caboatã da } \\
\text { folha grande }\end{array}$ & 13 & SI & $\mathrm{ZOO}$ \\
\hline SAPOTACEAE & Manilkara sp. & Leiteiro & 4 & $\mathrm{SC}$ & ZOO E BAR \\
\hline URTICACEAE & Cecropia hololeuca Miq. & Embaúba & 1 & $\mathrm{P}$ & $\mathrm{ZOO}$ \\
\hline VERBANACEAEA & Vitex polygama Cham. & Senhora vó & 8 & SI & $\mathrm{ZOO}$ \\
\hline FNI* & ENI* & NI2 & 5 & $\mathrm{SC}$ & -- \\
\hline
\end{tabular}

*Família e espécies Não Identificadas.

Fonte: Autores. 
Lima et al. (2017a); Lima et al. (2017b); Silva et al. (2020); Silva \& Moura (2021), registraram que em fragmentos florestais de Mata Atlântica de Pernambuco uma riqueza das famílias Fabaceae, Sapindaceae, Myrtaceae e Melastomataceae.

A Fabaceae representa uma das famílias das angiospermas mais representativas em estudos, devido sua ampla distribuição nos ecossistemas, qualidade ornamental e importância ecológica (Rodrigues et al., 2018). Silva et al. (2020). Os autores ainda ressaltam a importância das fabaceas na melhoria da qualidade e fertilidade do solo, promovido pelo processo de co-evolução entre as plantas desta família com bactérias fixadoras de nitrogênio.

A riqueza de espécies da família Myrtaceae é um bom indicador de regeneração natural dos ecossistemas, devido seus frutos suculentos e cornos serem atrativos para fauna silvestre, favorecendo a dispersão das sementes e permanência das espécies (Moraes et el., 2014).

No entanto, vários indivíduos menores que o DAP estabelecido foram observados por Silva (2001) e mostra que o número muito elevado de espécies que ocorrem com apenas um indivíduo amostrado, indica uma alta susceptibilidade à extinção local da espécie no fragmento, caso ocorra morte ou corte dos mesmos.

$\mathrm{Na}$ área de estudo, a Sapotaceae apresenta somente uma espécie não identificada do gênero das Manilkara sp. Mas esse gênero, em especial, a espécie Manilkara dardanoi Ducke, é considerada na Floresta Atlântica Nordestina nos Brejos de Altitude de Pernambuco, uma espécie endêmica (Tabarelli e Santos, 2004). Esses brejos são considerados o centro de endemismo (Prance, 1987). Melo e Radal (2003) evidenciaram em seus estudos o mesmo gênero das Manilkara sp., identificando a espécie Manilkara rufula (Miq.) Lam.

$\mathrm{Na}$ área de estudo foram classificadas 23 espécies arbóreas quanto ao seu grupo ecológico sucessional (Tabela 1). O grupo que mais se destacou foi secundária inicial representando $44 \%$ das espécies, seguidas das pioneiras por $26 \%$ das espécies; $17 \%$ não classificadas e $13 \%$ foram consideradas como secundária tardia. Do conjunto de espécies não classificadas quanto ao grupo ecológico, se referem a não identificação quanto família/espécie, a identificação somente da família e identificação família/gênero.

De acordo com Tabarelli e Mantovani (1999) a "flora futura", dominada por espécies de Melastomataceae e Myrsinaceae, entre outras, já tem sido observada em pequenos fragmentos florestais e em áreas de regeneração nos Brejos de Altitude pernambucano. No entanto, pode-se observar que as espécies dessas famílias encontradas na área de estudo são classificadas como secundárias iniciais, e esse mesmo grupo ecológico foi o mais representativo com $44 \%$ das espécies catalogadas (Figura 2). Durães et al. (2014) relataram que a porcentagem elevada de secundárias iniciais em uma área pode ser explicada por algum tipo de fragmentação, distúrbio ou perturbação ocorrida anteriormente. Paula et.al. (2004) caracterizou 94 espécies arbóreas/arbustivas em Viçosa - MG e obteve 59,6\% de espécies secundária iniciais. Enquanto que o trabalho desenvolvido no munícipio de Sirinhaém - PE, das 58 espécies amostradas, 47\% foram classificadas como secundárias iniciais (Silva et al., 2010).

A maior influência no presente estudo foi exercida pelas espécies secundárias iniciais, estando as pioneiras também presentes com relativa importância. As secundárias tardias, representando $13 \%$, são espécies que se encontram em ciclo de vida adulto em fase de frutificação, como é o caso da espécie Myrcia selloi (Spreng.) N. Silveria.

Quanto ao mecanismo de dispersão, as espécies foram classificadas em zoocóricas, anemocóricas, barocóricas e autocóricas. A categoria com maior representatividade na dispersão dos diásporos foi a zoocórica, com $73 \%$, seguida da anemocórica com 15\%, barocórica com $8 \%$ e autocórica com $4 \%$ das espécies. Das espécies zoocóricas que estavam em fase de frutificação encontram-se a Myrcia selloi (Spreng.) N. Silveria, Myrcia bela Cambess., Talisia esculenta (A.St.-Hil.) Radlk., Byrsonima sericea DC., cujos frutos são do tipo baga globosa, drupa negra, baga globosa, drupa globosa, respectivamente, que são frutos bastante procurados pela avifauna. 
A pesquisa realizada em um trecho de mata ciliar, Sirinhaém, Pernambuco, Brasil, relata que 72,8\% das espécies apresentaram síndrome de zoocoria, 13,6\% anemocoria e 4,8\% autocoria (Silva et al., 2012). Segundo Gomes (2018) as matas ciliares favorecem a zoocoria, pois permitem a manutenção de uma fauna devido a maior disponibilidade de água e por estarem protegidas do fogo. Diante disso, a porcentagem de espécies tende a aumentar a medida em que as florestas se tornam mais úmidas e apresentam uma menor estacionalidade climática, enquanto que as plantas dispersas pelo vento seriam mais comuns em florestas secas (Azevedo et al., 2018).

Quanto maior a diversidade da composição florística maior será a diversidade da composição faunística, que promoverá a dispersão dos diásporos devido a busca constante de alimentos. Os principais animais responsáveis pelo mecanismo de dispersão na área estudada ocorrem por pássaros (ornitocoria), por mamíferos (mamaliocoria) e por morcegos (quiropterocoria). A espécie Vitex polygama Cham., por exemplo, é bastante procurada pelos morcegos e periquitos, e seus frutos são do tipo drupa globosa. Lorenzi (2008) salienta que os frutos dessa espécie são avidamente consumidos por periquitos e papagaio e por outras espécies da fauna.

$\mathrm{Na}$ área amostrada, a família Sapindaceae uma das que representa o maior número de espécies por dispersão zoocórica, igualmente ocorre com as espécies que representam a família Myrtaceae. Ao contrário da família Fabaceae Faboideae rica em número de espécies, porém a dispersão se faz principalmente por anemocoria. Trabalho realizado por Stefanello et al. (2010) que retratam a síndrome de dispersão de diásporos das espécies de trechos de vegetação ciliar do Rio das Pacas, Querência - MT, confirmam o mecanismo de dispersão ocorrida pelas espécies relacionada às famílias botânicas da Melastomaceae, Sapindaceae, Myrtaceae e Fabaceae.

\subsection{Estrutura Fitossociológica Horizontal}

$\mathrm{Na}$ Tabela 2 se encontram as espécies amostradas no levantamento fitossociológico, em que a densidade absoluta total da comunidade estudada, considerando os indivíduos arbóreos com DAP $\geq 5,0 \mathrm{~cm}$, foram de 3.671,43 ind ha- ${ }^{-1}$. A área basal (dominância) para a comunidade foi de $18 \mathrm{~m}^{2}$ ha-1. A espécie Cupania impressinervia Acev.-Rodr. foi a melhor representada com 485,71 ind ha- ${ }^{1}$ em densidade absoluta, seguida da espécie Byrsonima sericea DC. com 471,43 ind ha- ${ }^{1}$.

Em estudos realizados em um Brejo de Altitude em Pesqueira - PE, a densidade absoluta foi 4.550 ind ha-1 e a área basal 62,8 $\mathrm{m}^{2}$ ha-1 ${ }^{1}$, sendo esta última a maior entre os brejos nordestinos (Pinto et al., 2012), levando em consideração que o estudo mencionado incluiu arbustos e árvores com diâmetro basal $\geq 3 \mathrm{~cm}$, o que possibilita o aumento de números de indivíduos por área. Ainda no mesmo trabalho, a espécie mais bem representada quanto à densidade absoluta foi a Coussarea contracta, na qual não ocorre na área estudada, o que demonstra a diferença de espécies mesmo em grupos florísticos semelhantes como os Brejos de Altitude. 


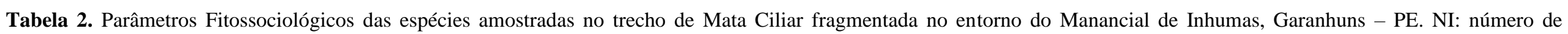

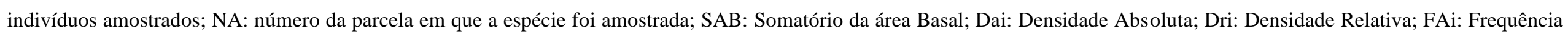

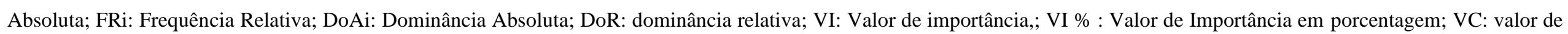
cobertura e VC \%: Valor de Cobertura em porcentagem.

\begin{tabular}{|c|c|c|c|c|c|c|c|c|c|c|c|c|c|}
\hline ESPÉCIES & $\mathrm{NI}$ & NA & $\begin{array}{c}\text { SAB } \\
\left(\mathrm{m}^{2} / \mathrm{ha}\right)\end{array}$ & $\begin{array}{c}\text { DAi } \\
\text { (Ind/há) }\end{array}$ & $\begin{array}{l}\text { DRi } \\
(\%)\end{array}$ & $\begin{array}{l}\text { FAi } \\
(\%)\end{array}$ & $\begin{array}{l}\text { FRi } \\
(\%)\end{array}$ & $\begin{array}{c}\text { DoAi } \\
\text { (m²/há) }\end{array}$ & $\begin{array}{c}\text { DoRi } \\
(\%)\end{array}$ & VI & $\begin{array}{l}\mathrm{VI} \\
(\%)\end{array}$ & $\mathrm{VC}$ & $\begin{array}{l}\mathrm{VC} \\
(\%)\end{array}$ \\
\hline Bowdichia virgilioides Kunth & 2 & 2 & 0,01235 & 28,57 & 0,78 & 28,57 & 2,53 & 0,18 & 0,98 & 4,29 & 1,43 & 1,76 & 0,88 \\
\hline Byrsonima sericea DC. & 33 & 7 & 0,20980 & 471,43 & 12,84 & 100,00 & 8,86 & 3,00 & 16,65 & 38,35 & 12,78 & 29,49 & 14,75 \\
\hline Casearia sylvestris $\mathrm{Sw}$. & 22 & 7 & 0,05319 & 314,29 & 8,56 & 100,00 & 8,86 & 0,76 & 4,22 & 21,64 & 7,21 & 12,78 & 6,39 \\
\hline Cecropia hololeuca Miq. & 1 & 1 & 0,00283 & 14,29 & 0,39 & 14,29 & 1,27 & 0,04 & 0,22 & 1,88 & 0,63 & 0,61 & 0,31 \\
\hline Cupania impressinervia Acev.-Rodr. & 34 & 7 & 0,12239 & 485,71 & 13,23 & 100,00 & 8,86 & 1,75 & 9,71 & 31,80 & 10,60 & 22,94 & 11,47 \\
\hline Cupania oblongifolia Mart. & 13 & 2 & 0,04640 & 185,71 & 5,06 & 28,57 & 2,53 & 0,66 & 3,68 & 11,27 & 3,76 & 8,74 & 4,37 \\
\hline Erythrina velutina Willd & 1 & 1 & 0,00785 & 14,29 & 0,39 & 14,29 & 1,27 & 0,11 & 0,62 & 2,28 & 0,76 & 1,01 & 0,51 \\
\hline Fabaceae sp. & 5 & 2 & 0,01950 & 71,43 & 1,95 & 28,57 & 2,53 & 0,28 & 1,55 & 6,02 & 2,01 & 3,49 & 1,75 \\
\hline Guatteria australis A.St.-Hil. & 1 & 1 & 0,00196 & 14,29 & 0,39 & 14,29 & 1,27 & 0,03 & 0,16 & 1,81 & 0,60 & 0,54 & 0,27 \\
\hline Hymenaea courbaril L. & 21 & 2 & 0,31583 & 300,00 & 8,17 & 28,57 & 2,53 & 4,51 & 25,07 & 35,77 & 11,92 & 33,24 & 16,62 \\
\hline Machaerium hirtum (Vell) Stellfeld & 9 & 5 & 0,04220 & 128,57 & 3,50 & 71,43 & 6,33 & 0,60 & 3,35 & 13,18 & 4,39 & 6,85 & 3,43 \\
\hline Manilkara sp. & 4 & 3 & 0,00827 & 57,14 & 1,56 & 42,86 & 3,80 & 0,12 & 0,66 & 6,01 & 2,00 & 2,21 & 1,11 \\
\hline Miconia minuflora Triana & 6 & 3 & 0,02162 & 85,71 & 2,33 & 42,86 & 3,80 & 0,31 & 1,72 & 7,85 & 2,62 & 4,05 & 2,03 \\
\hline Miconia sp. & 17 & 5 & 0,06912 & 242,86 & 6,61 & 71,43 & 6,33 & 0,99 & 5,49 & 18,43 & 6,14 & 12,10 & 6,05 \\
\hline Myrcia bela Cambess. & 29 & 7 & 0,09513 & 414,29 & 11,28 & 100,00 & 8,86 & 1,36 & 7,55 & 27,70 & 9,23 & 18,83 & 9,42 \\
\hline Myrcia selloi (Spreng.) N. Silveria & 8 & 5 & 0,02075 & 114,29 & 3,11 & 71,43 & 6,33 & 0,30 & 1,65 & 11,09 & 3,70 & 4,76 & 2,38 \\
\hline Myrsine umbellata Mart. & 1 & 1 & 0,00196 & 14,29 & 0,39 & 14,29 & 1,27 & 0,03 & 0,16 & 1,81 & 0,60 & 0,54 & 0,27 \\
\hline Talisia esculenta (A.St.-Hil.) Radlk. & 24 & 4 & 0,08946 & 342,86 & 9,34 & 57,14 & 5,06 & 1,28 & 7,10 & 21,50 & 7,17 & 16,44 & 8,22 \\
\hline
\end{tabular}


Research, Society and Development, v. 10, n. 4, e10910413900, 2021

(CC BY 4.0) | ISSN 2525-3409 | DOI: http://dx.doi.org/10.33448/rsd-v10i4.13900

\begin{tabular}{|c|c|c|c|c|c|c|c|c|c|c|c|c|c|}
\hline Tapirira guianensis Aubl. & 1 & 1 & 0,00196 & 14,29 & 0,39 & 14,29 & 1,27 & 0,03 & 0,16 & 1,81 & 0,60 & 0,54 & 0,27 \\
\hline Vismia brasiliensis Pers. & 8 & 4 & 0,02641 & 114,29 & 3,11 & 57,14 & 5,06 & 0,38 & 2,10 & 10,27 & 3,42 & 5,21 & 2,60 \\
\hline Vitex polygama Cham. & 8 & 4 & 0,05360 & 114,29 & 3,11 & 57,14 & 5,06 & 0,77 & 4,25 & 12,43 & 4,14 & 7,37 & 3,68 \\
\hline Zanthoxylum rhoifolium Lam. & 4 & 3 & 0,02443 & 57,14 & 1,56 & 42,86 & 3,80 & 0,35 & 1,94 & 7,29 & 2,43 & 3,50 & 1,75 \\
\hline$N I 2 *$ & 5 & 2 & 0,01288 & 71,43 & 1,95 & 28,57 & 2,53 & 0,18 & 1,02 & 5,50 & 1,83 & 2,97 & 1,48 \\
\hline TOTAL & 257 & 7 & 1,26 & 3671,4 & 100 & 1128,6 & 100 & 18,00 & 100 & 300 & 100 & 200 & 100 \\
\hline
\end{tabular}

*NI Espécie Não Identificada.

Fonte: Autores. 
As espécies Byrsonima sericea DC., Myrcia bela Cambess., Cupania impressinervia e Casearia sylvestris Sw. estão presentes em todas as parcelas levantadas, e, portanto, obtiveram frequência absoluta de 100\%. Enquanto as espécies Tapirira guianensis Aubl., Guatteria australis, Erythrina velutina, Myrsine umbellata Mart. e Cecropia hololeuca Miq. estiveram presentes somente em uma parcela e são as que representam somente um indivíduo na área amostrada, exceto a Tapirira guianensis que foi constatado vários indivíduos com DAP menor $5 \mathrm{~cm}$ (Tabela 02). Portanto, espécies somente com um indivíduo são consideraras raras em levantamento florísticos, podem estar em processo de extinção ou substituição local, ou ainda começando a se estabelecer na área (Leão et al., 2017).

As mesmas espécies, que obtiveram maior representatividade no parâmetro de frequência, sendo que as três juntas detêm de $37,35 \%$ do total de indivíduos por hectare.

Em relação à área basal que compreende o parâmetro da dominância absoluta, a espécie com maior representatividade foi Hymenaea courbaril L., seguida da Byrsonima sericea DC. A espécie que mais se destacou no parâmetro da dominância foi a Hymenaea courbaril L., ao contrário da Cupania impressinervia que ocupou primeiro lugar no parâmetro de frequência e densidade, porém na dominância ficou bem abaixo comparado com a Hymenaea courbaril L. A dominância absoluta é a relação da área basal da espécie por unidade de área, nesse caso a área basal está relacionado ao diâmetro do fuste, caracterizando o domínio da biomassa da espécie Hymenaea courbaril L. na área, já que seu DAP médio alcançou $13 \mathrm{~cm}, \mathrm{o}$ DAP médio da Byrsonima sericea DC. foi de $8,7 \mathrm{~cm}$ e Cupania impressinervia foi de $6,5 \mathrm{~cm}$.

Em relação ao valor de importância, a espécie Byrsonima sericea DC. se destacou, seguida da Hymenaea courbaril L., em terceiro lugar está Cupania impressinervia e em quarto a espécie Myrcia bela Cambess.

As espécies com os maiores valores de importância consequentemente são as que obtiveram os maiores valores de frequência, densidade e dominância relativa, pois o valor de importância é o somatório desses resultados e atribui a essas espécies, maior importância ecológica dentro dessa comunidade vegetal (Oestreich Filho, 2014).

A espécie Byrsonima sericea DC. foi encontrada em total em todas as parcelas, e foi umas das que alcançou o máximo de indivíduos por hectare na área amostrada, perdendo somente para Cupania impressinervia, quanto a dominância, sendo a segunda de melhor representatividade e maior valor de importância.

A Hymenaea courbaril L. foi caracterizada como a segunda espécie em valor de importância devido ao porte de sua biomassa que lhe atribuiu na melhor posição no parâmetro da dominância, apesar de ocorrer somente em duas parcelas, ao contrário da Cupania impressinervia que obteve frequência absoluta de 100\%, sendo a espécie que alcançou o maior número de indivíduos por hectare, no entanto regrediu na dominância, o que a fez ficar em terceira espécie de valor de importância.

Quando analisado o valor de cobertura a espécie que mais se destacou foi a Hymenaea courbaril L. devido a sua melhor representatividade na dominância, na sequência foi a espécie Byrsonima sericea DC.

A espécie Hymenaea courbaril L. pertence à família da Fabaceae Caesalpinioideae é bem distribuída no território brasileiro, principalmente em Floresta Estacional Semidecidual Montana e Matas Ciliares. Está inclusa no grupo ecológico da secundária tardia, apresentando dispersão dos seus diásporos por autocoria, barocoria e zoocoria (Tabela 1). Em relação a zoocoria, a dispersão é representada pelos mamíferos, que procuram a polpa farinácea do fruto para a alimentação, promovendo a dispersão das sementes para ambientes mais distantes. A distribuição dessa espécie na área amostrada ocorreu nas parcelas 1 e 3 conforme representado na Figura 9, em que os indivíduos estão localizados no ponto mais alto da área e apresentam distribuição agregada, ocorrendo com maior frequência na parcela 1. Estudos como de Ribeiro et al. (2011) confirmam as características ecológicas e sobre sua distribuição discriminada da espécie $H$. courbaril L.

A Byrsonima sericea DC. foi a espécie que se destacou em maior importância ecológica dentro da comunidade vegetal amostrada e a segunda em valor de cobertura. Pertencente à família da Malpighiaceae, ocorre em Florestas Estacional Semidecidual, em formações arbustivas em margens de rios e em área de restinga. Classificada como secundária inicial, sua 
dispersão se faz por zoocoria e seu fruto é do tipo drupa globosa, suas flores são produtoras de óleos e polinizadas por abelhas especialistas em coletar óleos e pólen (Francener, 2021). Isso caracteriza um exemplo de planta com considerável dependência do mutualismo planta-polinizador (Dunley, 2006). A frequência da B. sericae DC. na área de estudo ocorreu 100\% em todas as parcelas, porém a parcela que obteve maior número de indivíduos foi na parcela seis com $39 \%$, localizada nas margens do manancial de Inhumas (Figura 9). Trabalhos realizados com espécie Byrsonima sericea DC confirmam suas características (Anderson, 1979; Dunley, 2006; Silva et al., 2013).

A espécie Cupania impressinervia Acev.-Rodr foi a terceira colocada no valor de importância e valor de cobertura, porém a primeira em densidade absoluta. Essa espécie pertence à família da Sapindaceae, específica da Mata Atlântica Nordestina e endêmica do Brasil (Pereira et al., 2016). Estudo realizado pelo Jardim Botânico de Recife - JBR e Fundação de Amparo a Ciência de Pernambuco - Facepe (2013), concluiu que a C. impressinervia Acev.-Rodr. se encontra ameaçada de extinção, pertence ao grupo da secundária inicial, com mecanismo de dispersão zoocórica e seus frutos são do tipo cápsulas deiscentes, suas sementes apresentam excrescência alaranjada (Pereira et al., 2016), denominado arilo, sendo responsável pela atratividade da avifauna. Com 34 indivíduos, a C. impressinervia Acev.-Rodr ocorreu 100\% em todas parcelas, possuindo uma maior representatividade na parcela dois com 35\% dos indivíduos, na qual estão distribuídos de forma agregada.

A família que obteve maior valor de importância foi a Sapindaceae, representando 21,5\%, seguido da Myrtaceae com $12,9 \%$ e em terceiro a família da Malpighiaceae com 12,8 \%. A família da Sapindaceae foi representada pelas espécies Cupania impressinervia Acev.-Rodr., Talisia esculenta (A.St.-Hil.) Radlk. e Cupania oblongifolia Mart. com 34, 24 e 13 indivíduos respectivamente.

\subsection{Estrutura Fitossociológica Vertical}

Todos os indivíduos arbóreos com DAP $\geq 5 \mathrm{~cm}$ foram medidos quanto a sua altura e classificados de acordo com os extratos 1, 2 e 3 (Tabela 3). O extrato 1 compõe as espécies que se enquadram nas alturas até 5,0 m, o extrato 2 representa as espécies de 5,1-7,0 m e o extrato 3 representa a parte superior da mata, o dossel, ocorrendo acima de 7,1 m.

Dos 257 indivíduos amostrados pelo método da posição sociológica, 56\% pertencem ao estrato inferior, 34\% pertencem ao estrato médio e $10 \%$ ao estrato superior.

O extrato 1 obtendo melhor representatividade na área de estudo, em que foi constatado 144 indivíduos que corresponde a todas as espécies, exceto a espécie Cecropia hololeuca Miq. Pertencendo somente ao extrato superior contendo um indivíduo (Tabela 3). Trabalho realizado por Silva et al. (2003) revela que algumas espécies, embora pioneiras, alcançam o dossel e permanecem à luz mesmo depois do maior desenvolvimento da floresta, das quais encontram-se indivíduos jovens nas áreas com grande penetração de luz, entre estas destaca-se Cecropia hololeuca Miq.

A maior quantidade de indivíduos no extrato 1 indica que o trecho de floresta amostrado se encontra em estágio maduro inicial, em fase de crescimento, algumas espécies em florescimento e frutificação como Vismia brasiliensis Pers., Casearia sylvestris Sw., Byrsonima sericea DC, Miconia minutiflora Triana, Myrcia selloi (Spreng.) N. Silveria, Myrcia bela Cambess. e Cupania oblongifolia Mart. A espécie Talisia esculenta (A.St.-Hil.) Radlk., por exemplo, se encontra no estágio maduro inicial em fase de crescimento, com uma altura e DAP médio, de 4,9 m e 6,6 cm, respectivamente. Estudos confirmam que essa espécie pode alcançar de 5 a 15 m de altura, e seu tronco de 30 a 40 cm de diâmetro (Lorenzi, 2006; Goés, 2011). 
Tabela 3. Número de indivíduos de cada estrato correspondente a determinada espécie amostradas no trecho de mata ciliar fragmentado no entorno do manancial de Inhumas, Garanhuns - PE.

\begin{tabular}{|c|c|c|c|c|}
\hline FAMÍLIA/ESPÉCIE & NOME POPULAR & $\begin{array}{c}\text { EXT. 1 } \\
(<5,0 \mathrm{M})\end{array}$ & $\begin{array}{c}\text { EXT. } 2 \\
(5,1-7,0 \mathrm{M})\end{array}$ & $\begin{array}{c}\text { EXT. } 3 \\
(>7,1 \mathrm{M})\end{array}$ \\
\hline
\end{tabular}

\section{ANACARDIACEAE}

Tapirira guianensis Aubl.

Pau pombo

\section{ANNONACEAE}

Guatteria australis A.St.-Hil.

Pindaúva preta

\section{CLUSIACEAE}

Vismia brasiliensis Pers.

Lacre

\section{FABACEAE}

\section{CAESALPINIOIDEAE}

Hymenaea courbaril L.

Jatobá

\section{FABACEAE - FABOIDEAE}

Machaerium hirtum (Vell) Stellfeld

Chifre de bode

Bowdichia virgilioides Kunth

Sucupira preto

Mulungu

Erythrina velutina Willd.

\section{FABACEAE MIMOSOIDAE}

NI 1*

\section{FLACOURTIACEAE}

Casearia sylvestris $\mathrm{Sw}$.

\section{MALPIGHIACEAE}

Byrsonima sericea DC.

\section{MELASTOMATACEAE}

\author{
Miconia sp. \\ Miconia minutiflora Triana
}

\section{MYRSINACEAE}

Myrsine umbellata Mart.

\section{MYRTACEAE}

Myrcia selloi (Spreng.) N. Silveria Myrcia bela Cambess.

\section{RUTACEAE}

Zanthoxylum rhoifolium Lam.

\section{SAPINDACEAE}

Talisia esculenta(A.St.-Hil.) Radlk.

Cupania impressinervia Acev.-Rodr.

Cupania oblongifolia Mart.
NI 1

1

4

Caimbim

Murici

9

14

10

$\begin{array}{lll}\text { Cinzeiro } & 9 & 8 \\ \text { Cinzeiro da } & 5 & 1\end{array}$

Pororocão

Murta

Pitomba 17

7

Caboatã do rêgo 


\section{SAPOTACEAE}

Manilkara sp.

Leiteiro

2

2

\section{URTICACEAE}

Cecropia hololeuca Miq.

Embaúba

\section{VERBANACEAEA}

Vitex polygama Cham.

Senhora vó

2

5

1

Família NI*

\begin{tabular}{ccccc} 
NI 2* & NI2 & 4 & 1 & \\
\hline & TOTAL DE INDIVÍDUOS & 144 & 87 & 26 \\
\hline
\end{tabular}

*Família e espécies Não Identificadas

Fonte: Autores.

As espécies que ocuparam os três extratos foram a Cupania impressinervia Acev.-Rodr., Byrsonima sericea DC., Zanthoxylum rhoifolium Lam., Vitex polygama Cham., e Hymenaea courbaril L., revelando a expansão vertical nos diferentes extratos arbóreos. A maioria das espécies estão em processo de expansão do extrato 1 para o extrato 2. A C. impressinervia Acev.-Rodr. foi a melhor representada com números de indivíduos no extrato 1.

A estrutura sociológica informa a composição florística dos vários estratos da floresta, no sentido vertical, e do papel que desempenham as diferentes espécies em cada um dos estratos (Lamprecht, 1990; Hosokawa et al., 2008). Dessa forma a Tabela 4 demonstra a posição sociológica que se encontra a comunidade florística amostrada. 
Tabela 4. Posição sociológica no extrato vertical das espécies identificadas no trecho de mata ciliar fragmentado no entorno do manancial de Inhumas, Garanhuns - PE. NI: Número de Indivíduos; PSAi: Posição Sociológica Absoluta; PSRi: Posição Sociológica Relativa.

\begin{tabular}{|c|c|c|c|}
\hline ESPÉCIES & $\mathrm{NI}$ & PSAi & PSRi $\%$ \\
\hline Bowdichia virgilioides Kunth & 2 & 0,66 & 0,59 \\
\hline Byrsonima sericea DC. & 33 & 10,8 & 9,57 \\
\hline Casearia sylvestris $\mathrm{Sw}$. & 22 & 11,22 & 9,95 \\
\hline Cecropia hololeuca Miq. & 1 & 0,1 & 0,09 \\
\hline Cupania impressinervia Acev.-Rodr. & 34 & 16,6 & 14,71 \\
\hline Cupania oblongifolia Mart. & 13 & 5,96 & 5,28 \\
\hline Erythrina velutina Willd. & 1 & 0,56 & 0,50 \\
\hline Guatteria australis A.St.-Hil. & 1 & 0,56 & 0,50 \\
\hline Hymenaea courbaril $\mathrm{L}$. & 21 & 4,72 & 4,18 \\
\hline Machaerium hirtum (Vell) Stellfeld & 9 & 4,38 & 3,88 \\
\hline Manilkara sp. & 4 & 1,8 & 1,60 \\
\hline Miconia minuflora Triana & 6 & 3,14 & 2,78 \\
\hline Miconia sp. & 17 & 7,76 & 6,88 \\
\hline Myrcia bela Cambess. & 29 & 14,92 & 13,22 \\
\hline Myrcia selloi (Spreng.) N. Silveria & 8 & 4,04 & 3,58 \\
\hline Myrsine umbellata Mart. & 1 & 0,56 & 0,50 \\
\hline$N I 1^{*}$ & 5 & 1,92 & 1,70 \\
\hline$N I 2 *$ & 5 & 2,58 & 2,29 \\
\hline Talisia esculenta (A.St.-Hil.) Radlk. & 24 & 11,9 & 10,55 \\
\hline Tapirira guianensis Aubl. & 1 & 0,56 & 0,50 \\
\hline Vismia brasiliensis Pers. & 8 & 3,82 & 3,39 \\
\hline Vitex polygama Cham. & 8 & 2,92 & 2,59 \\
\hline Zanthoxylum rhoifolium Lam. & 4 & 1,34 & 1,19 \\
\hline TOTAL & 257 & 112,82 & 100,00 \\
\hline
\end{tabular}

*NI Espécie Não Identificadas Fonte: Autores.

A espécie Cupania impressinervia foi destaque mais uma vez na posição sociológica do extrato vertical arbóreo, ocupando os três extratos. De acordo com Schorn (2012), a posição sociológica da C. impressinervia indica que a espécie se encontra estável e tem seu lugar assegurado na estrutura da floresta, pois apresenta densidade decrescente dos estratos inferiores para os superiores.

\section{Conclusão}

A área de Floresta Estacional Semidecidual com 0,13 ha, localizado no entorno do manancial de Inhumas, Garanhuns - PE, possui 257 indivíduos arbóreos reunidos em 23 espécies pertencentes a 15 famílias. A área possui alta riqueza florística destacando as famílias Fabaceae e Sapindaceae e a composição florística do fragmento está em fase inicial do desenvolvimento sucessional, em que $44 \%$ são do grupo ecológico das secundárias iniciais e $26 \%$ das pioneiras. 
O principal mecanismo de dispersão de sementes no fragemento é zoocoria (76\%), a dispersão dos diásporos ocorre principalmente por ornitocoria, mamaliocoria e quiropterocoria. As espécies com maior densidade absoluta foi a Cupania impressinervia Acev.- Rodr., Byrsonima sericea BC. e Myrcia bela Cambess. e as espécies com dominância na área é o Hymenaea courbaril L., seguida da Byrsonima sericea BC. A estrutura vertical relacionada ao parâmetro posição sociológica mostram que dos 257 indivíduos, $56 \%$ pertencem ao estrato inferior, $34 \%$ pertencem ao estrato médio e $10 \%$ ao estrato superior, sendo a espécie Cupania impressinervia Acev.-Rodr. a maisr representada na posição sociológica do extrato vertical arbóreo, ocupando os três extratos. A flora estudada está em processo de regeneração natural e a maioria das espécies estão em processo de expansão do extrato 1 para o extrato 2.

As pesquisas em composição florística e fitossociológica da vegetação são de extrema importância e são necessários mais estudos nos remanescentes dos brejos de altitudes em Garanhuns para maior conhecimento das espécies e elaboração de uma lista mais ampla, que possam ser utilizadas futuramente para recuperação desses ambientes e também identificação daquelas espécies endêmicas que estejam em processo de extinção.

\section{Agradecimentos}

Ao Dr. Marcondes Oliveira pelo auxílio na identificação botânica das espécies florestais e a Secretaria de Desenvolvimento Rural e Meio Ambiente de Garanhuns.

\section{Referências}

Apac. (2018). Histório Pluviométrico. Website da Agência Pernambucana de Águas e Climas - APAC. www.apac.pe.gov.br/meteorologia/

Araújo, H. H. R., Souza, F. B. M., Pio, R., Freire, A. I., Pereira, A. M., Cruz, R. R. P., Pimentel, R. M., Melo, C. C. V. \& Souza, A. J. M. Levantamento fitossociológico das plantas daninhas em diferentes frutíferas de clima temperado no Município de Lavras - MG. Research, Society and Development, 9(8), e964986553 10.33448/rsd-v9i8.6553

Araujo, T. G., QueirozI, A. B. \& Lopes, S. F. (2019). Fitossociologia de um brejo de altitude no semiárido brasileiro: variação das espécies dominantes ao longo do gradiente altitudinal. Ciências Florestais. 29(2), 779-794. https://doi.org/10.5902/1980509821231

Azevedo, A. D., Francelino, M. R., Camara, R., Pereira, M. G. \& Leles, P. S. S. (2018). Estoque de carbono em áreas de restauração Florestal da Mata Atlântica. Floresta, 48(2), 183-194. http://dx.doi.org/10.5380/rf.v48i2.54447

Brito, A., Ferreira, M. Z., Mello, J. M., Soares Scolforo, J. R., Donizette de Oliveira, A. \& Weimar Acerbi, F. (2007). Comparação Entre os Métodos de Quadrantes e PRODAN para Análises Florística, Fitossociológica e Volumétrica. Revista Cerne, 13(4), 399-405.

Carvalho, F. (2019). Cálculos da Estrutura Horizontal e Vertical. Website Mata Nativa. https://www.matanativa.com.br/calculos-da-estrutura-horizontal-evertical/\#: :text=A\%20estrutura\%20horizontal\%20\%C3\%A9\%20a,cobertura\%20de\%20 cada\%20esp\%C3\%A9cie\%20amostrada.

Cunha, M. C. L. \& Silva Júnior, M. C. (2014). Flora e estrutura de floresta estacional semidecidual montana nos estados da Paraíba e Pernambuco. Nativa, 2(2), 95-102. 10.31413/nativa.v2i2.1554

Cunha, M. C. L., Júnior, M. C. S. \& Lima, R. B. (2013). Fitossociologia do estrato lenhoso de uma floresta estacional semidecidual montana na Paraíba, Brasil. Cerne. 19(2), 271-280. https://doi.org/10.1590/S0104-77602013000200011

Dunley, B. S. (2006). Biologia reprodutiva de Byrsonima sericea(Malpighiaceae), em fragmentos de diferentes tamanhos na Restinga de Massambaba, Arraial do Cabo, Rio de Janeiro (Dissertação de Mestrado). Instituto de Pesquisa Jardim Botânico do Rio de Janeiro. RJ. Brasil.

Durães, M. C. O., Sales, N. L P., Neto, S. D. \& Figueiredo, M. A. P. (2014). Levantamento florístico do estrato arbóreo de três fragmentos de floresta ciliar como subsídio à recomposição da vegetação do rio cedro, Montes Claros - MG. Ciência Florestal, 24(1), 47-58. https://doi.org/10.5902/1980509813322

Flora do Brasil. (2020). Jardim Botânico do Rio de Janeiro. Website do Jardim botânico do Rio de Janeiro. http://floradobrasil.jbrj.gov.br/.

Francener, A. (2021). Byrsonima in Flora do Brasil 2020. Website Jardim Botânico do Rio de Janeiro. http://reflora.jbrj.gov.br/reflora/floradobrasil/FB8845

Galindo Leal, C. E. \& Câmara, I. G. (2005). Mata Atlântica: Biodiversidade, Ameaças e Perspectivas. Conservação Internacional.

Góes, G. B. (2011). Propagação do Tamarindeiro (Tamarindus indica L.) e da Pitombeira (Talisia esculentaRaldk) por enxertia (Dissertação Mestrado). Universidade Federal Rural do Semiárido, RN, Brasil.

Gomes, A. R. (2018). Monitoramento e avaliação da qualidade da água bruta da barragem inhumas e sua influência na qualidade da água tratada (Trabalho de Conclusão de Curso). Universidade Federal Rural de Pernambuco, PE, Brasil. 
Gomes, L. C. (2018). Síndromes de dispersão do estrato arbóreo-arbustivo em dois fragmentos florestais do Pantanal Sul, MS. Biodiversidade. 17(2), 139-149.

Google. (2018), Google Earth website. Website http://earth.google.com/.

Hosokawa, R. T., Moura, J. B. \& Cunha, U. S. (2008). Introdução ao Manejo e Economia de Florestas. UFPR.

Lamprecht, H. (1990). Ensayo sobre unos metodos para el análisis estructural de los bosques tropicales. Acta Cientifica Venezolana, 13(2), 57-65.

Leão, F. M., Dionisio, L. F. S., Silva, N. G. E., Oliveira, M. H. S., D’arace, L. M. B., Lobato, R. \& Neves, P. (2017). Fitossociologia em sistemas agroflorestais com diferentes idades de implantação no município de Medicilândia, PA. Revista Agroambiente, 11(1), 71-81. http://dx.doi.org/10.18227/19828470ragro.v11i1.3402

Lima, R. B. A., Marangon, L. C., Freire, F. J., Feliciano, A. L. P. \& Silva, R. K. S. (2017a). Potencial regenerativo de espécies arbóreas em fragmento de Mata Atlântica, Pernambuco, Brasil. Revista Verde de Agroecologia e Desenvolvimento Sustentável, 12(4), 666-673.

Lima, R. B. A., Silva, R. K. S., Paula, M. D., Guimarães, E. T. R. \& Braga, E. C. B. (2017b). Estrutura fitossociológica e diamétrica de um fragmento de mata atlântica, Pernambuco, Brasil. Revista Desafios, 4(4), 143-153. https://doi.org/10.20873/uft.2359-3652.2017v4n4p143

Lorenzi, H. \& Lacerda, M. (2006). Frutas Brasileiras e exóticas cultivadas (de consumo in natura). Instituto Plantarum.

Lorenzi, H. (2008). Árvores brasileiras: manual de identificação e cultivo de plantas arbóreas nativas do Brasil. Instituto Plantarum.

Lorenzoni-Paschoa, L. S., Abreu, K. M. P., Silva, G. F., Dias, H. M., Machado, L. A. \& Silva, R. D. (2019). Estágio sucessional de uma floresta estacional semidecidual secundária com distintos históricos de uso do solo no sul do Espírito Santo. Rodriguésia, 70, 1-18. https://doi.org/10.1590/2175-7860201970028

Marangon, L. C., Soares, J. J. \& Feliciano, A. L. P. (2003). Florística arbórea da mata da pedreira, município de viçosa, Minas Gerais. Revista Árvore. 27(2), 207-215.

Meira-Neto, J. A. A. \& Martins, F. R. (2002). Composição florística de uma floresta estacional semidecidual montana no município de Viçosa-MG. Revista Árvore, 26(4), 437-446. https://doi.org/10.1590/S0100-67622002000400006

Melo, J. I. M. \& Radal, M. J. N. (2003) Levantamento Florístico de um Trecho de Floresta Serrana no Planalto de Garanhuns, Estado de Pernambuco. Departamento de Biologia, Universidade Federal Rural de Pernambuco, 25(1), 173-178. 10.4025/actascibiolsci.v25i1.2120

MMA. (2002) Avaliação e Identificação de Áreas e Ações Prioritárias Para a Conservação, Utilização Sustentável e Repartição dos Benefícios da Biodiversidade nos Biomas Brasileiros. Ministério de Meio Ambiente.

Morais, L. M. F., Conceição, G. M. \& Nascimento, J. M. (2014). Família Myrtaceae: análise morfológica e distribuição geográfica de uma coleção botânica. Agrarian Academy, 1(1), 317-346.

Mueller Dombois, D. \& Ellenberg, H. (1974). Aims and methods of vegetation ecology. John Wiley.

Oestreich Filho, E. (2014). Fitossociologia, Diversidade e Similaridade entre Fragmentos de Cerrado Strict Sensu sobre neossolos quartzarênicos órticos, nos município de Cuiabá e Chapada dos Guimarães, Estado de Mato Grosso, Brasil (Dissertação de Mestrado). Universidade Federal de Mato Grosso, MG, Brasil.

Paula, A. L., Silva, A. F., Marco Junior, P., Santos, F. A. M. \& Souza, A. L. (2004). Sucessão ecológica da vegetação arbórea em uma Floresta Estacional Semidecidual. Acta Botanica Brasilica, 18(3), 407-423. https://doi.org/10.1590/S0102-33062004000300002

Peixoto, A. L. \& Maia, L. C. (2013). Manual para procedimentos em herbário. Editora universitária.

Pereira, L. A., Amorim, B. S., Alves, M., Somner, G. V. \& Barbosa, M. R. V. (2016). Flora da Usina São José, Igarassu, Pernambuco: Sapindaceae. Rodriguésia, 67(4), 1047-1059. https://doi.org/10.1590/2175-7860201667414.

Pinto, M. S. C., Sampaio, E. V. S. B. \& Nascimento, L. M. (2012). Florística e Estrutura da Vegetação de um Brejo de Altitude em Pesqueira, PE, Brasil. Revista Nordestina de Biologia, 21(1), 47-79. https://doi.org/10.5902/1980509821231

Porto, K. C., Cabral, J. J. P. \& Tabarelli, M. (2004). Brejos de altitude em Pernambuco e Paraíba: história natural, ecologia e conservação. Ministério do Meio Ambiente.

Prance, G. T. (1987), Biogeography of neotropical plants. America Claredon Press, 175-196.

Ribeiro, M. S., Rezende, S. L. \& Bernasol, W. P. (2011). Estrutura espacial e deposição de sementes de Hymenaea courbaril L. em um fragmento florestal no sudoeste goiano. Acta Scientiarum Biological Sciencs. 33(1), 41-47. 10.4025/actascibiolsci.v33i1.5881

Rodal, M. J. N., Sales, M. F., Silva, M. J. \& SILVA, A. G. (2005). Flora de um brejo de altitude na escarpa oriental do planalto da Borborema, PE, Brasil. Acta Botanica Brasilica, 19(4), 843-858. https://doi.org/10.1590/S0102-33062005000400020

Rodrigues, E. M., Queiroz, R. T., Silva, L. P., Monteiro, F. K. S \& Melo, J. I. M. Fabaceae em um afloramento rochoso no Semiárido brasileiro. Rodriguésia 71, 1-25. https://doi.org/10.1590/2175-7860202071025.

Schorn, L. A. S. (2012). Fitossociologia. Centro de Ciências Tecnológicas. Departamento de Engenharia Florestal. Universidade Regional de Blumenau.

Silva, A. F., Oliveira, R. V., Santos, N. R. L. \& Paula, A. (2003). Composição florística e grupos ecológicos das espécies de um trecho de floresta semidecídua submontana da fazenda são geraldo, Viçosa-MG. Revista árvore, 27(3), 311-319. https://doi.org/10.1590/S0100-67622003000300006. 
Research, Society and Development, v. 10, n. 4, e1091013900, 2021

(CC BY 4.0) | ISSN 2525-3409 | DOI: http://dx.doi.org/10.33448/rsd-v10i4.13900

Silva, I. S., Pinto, A. V. F., Almeida, C. A. C., Leite, M. J. H. \& Paes, R. A. (2020a). Levantamento das espécies arbóreas da Praça Centenário do município de Maceió, Alagoas. Acta Biológica Catarinense, 7(1), 29-36.

Silva, J. M. \& Moura, C. H. R. (2021). Análise da vegetação de um remanescente de Floresta Atlântica: subsídios para o projeto paisagístico. Revista Brasileira de Meio Ambiente, 9(1), 2-24.

Silva, L. A. (2001). Levantamento florístico e estrutura fitossociológica do estrato arbóreo de um fragmento de floresta estacional semidecidual no município de São Carlos - SP (Tese de Doutorado). Universidade Federal de São Carlos, SP, Brasil.

Silva, L. G., Brandão, C. F. L. S., Lana, M. D., Silva, A. F., Santos, A. A. L., Silva, N. L., Vieira, A. C. S. \& Pinto, A. V. F. (2020b). Florística, fitossociologia e caracterização ecológica numa área de capoeirão de Cabo de Santo Agostinho, Pernambuco. Brazilian Journal of Development. 6(6), 34519-34540. https://doi.org/10.34117/bjdv6n6-118

Silva, N. R. S., Martins, S. V., Neto, J. A. A. M. \& Souza, A. L. (2004). Composição florística e estrutura de uma floresta estacional semidecidual montana em Viçosa, MG. Revista Árvore, 28(3), 397-405. https://doi.org/10.1590/S0100-67622004000300011

Silva, R. K. S., Feliciano, A. L. P., Marangon, L. C., Lima, R. B. A. \& Santos, W. B. (2012). Estrutura e síndromes de dispersão de espécies arbóreas em um trecho de mata ciliar, Sirinhaém, Pernambuco, Brasil. Pesquisa Florestal Brasileira. 32(69), 1-11.

Silva, R. K. S., Feliciano, A. L. P., Rosiva,l L.C. M. \& Lima, B. A. (2010). Florística e sucessão ecológica da vegetação arbórea em área de nascente de um fragmento de Mata Atlântica, Pernambuco. Revista Brasileira de Ciências Agrárias, 5(4), 550-559.

Silva, R. K. S., Lima, R. B. A., Feliciano, A. L. P., Marangon, L. C. \& Silva, J. P. G. (2013). Grupos Ecológicos de Espécies Arbóreas, Sirinhaém, website da VIII Jornada de Ensino, Pesquisa e Extensão. Universidade Federal Rural de Pernambuco, http://www.eventosufrpe.com.br/2013/cd/resumos/R0431-3.pdf

Souza, V. C. \& Lorenzi, H. (2012). Botânica Sistemática: guia ilustrado para identificação das famílias de Fanerógramas nativas e exóticas no Brasil, baseado em APG III. Instituto Plantarum.

Stefanello, D., Ivanauskas, N. M., Martins, S. V., Silva, E. \& Kunz, S. H. (2010). Síndromes de dispersão de diásporos das espécies de trechos de vegetação ciliar do rio das Pacas, Querência - MT. ACTA Amazônica, 40(1), 14-50. https://doi.org/10.1590/S0044-59672010000100018.

Tabarelli, M. \& Mantovani, W. (1999). A regeneração de uma floresta tropical montana após corte e queima. Revista Brasileira de Biologia, 59, 239-250. https://doi.org/10.1590/S0034-71081999000200008

Tabarelli, M. \& Santos, A. M. M. (2004) Uma Breve Descrição Sobre a História Natural dos Brejos Nordestinos. Ministério do Meio Ambiente.

Torres, C. M. M. E., Jacovine, L. A. G., Neto, S. N. O., Souza, A. L., Campos, R. A. \& Schettini, B. L. S. (2017). Análise Fitossociológica e Valor de Importância em Carbono para uma Floresta Estacional Semidecidual. Floresta e Ambient, 24, 1-10. https://doi.org/10.1590/2179-8087.099714 